\title{
Analisis Penerapan Model Four Levers of Control (Studi Kasus PT. Indorama Synthetics Tbk Polyester Division di Purwakarta)
}

\author{
Muhammad Ardi Nupi Hasyim ${ }^{1}$, Setiandari Zamzami², Dewi Yanti ${ }^{3}$, Madeleine Ing Mandaku \\ 1,2,3,4 Prodi S1-Akuntansi Institut Manajemen Koperasi Indonesia \\ Kawasan Pendidikan Tinggi Jatinangor, Jl. Jatinangor KM. 20, 5, Cibeusi, Sumedang, Kabupaten Sumedang, \\ Jawa Barat 45363, Indonesia \\ e-mail: ${ }^{1}$ ardi.nupi@yahoo.com, ${ }^{2}$ tiandari20@gmail.com, ${ }^{3}$ dewiiynt@gmail.com, ${ }^{4}$ inemandaku2100@gmail.com
}

Informasi Artikel Diterima: 29-05-2021 Direvisi: 04-07-2021 $\quad$ Disetujui: 10-07-2021

\begin{abstract}
Abstrak
Sistem pengendalian manajemen dan arah manajer untuk setiap perusahaan berbeda. Dikarenakan adanya variabel yang membedakan setiap perusahaan. Oleh karena itu dalam penelitian ini akan menganalisis penerapan konsep teori Four Levers of Control di PT. Indorama Synthetics Tbk di kabupaten Purwakarta, konsep ini dapat meningkatkan kinerja karyawan. Objek penelitian ini adalah perusahaan tekstil dan barang kebutuhan lainnya. Penelitian ini menggunakan pendekatan kualitatif, metode sumber pengumpulan data untuk penelitian ini dilakukan dengan studi kepustakaan, wawancara dan analisis data. Setiap perusahaan membutuhkan tuas kendali yang beragam dan kompatibel dengan kondisi perusahaan; Pada Analisis Belief Systems dimana perusahaan telah memotivasi karyawan untuk menerapkan dan nilai dan telah memiliki suatu visi, misi dan tata nilai yang sesuai dengan aturan perusahaan. Pelaksanaan system belief systems ini telah dikomunikasikan melalui berbagai media seperti bingkai yang ditempel di dinding kantor, di website perusahaan, ditampilkan pada pertemuan-pertemuan internal dan pada saat proses rekrutmen karyawan baru ditanyakan mengenai visi misi perusahaan. Boundary Systems ini perusahaan menunjukkan bahwa telah merealisasikan batasan tersebut melalui adanya batasan perilaku yang telah ditetapkan, dimana perusahaan PT.Indorama Synthetics Tbk ini telah memuat aturan-aturan yang jelas dan komprehensif dengan adanya sanksi atas pelanggaran pedoman perilaku tersebut. Diagnostic Control Systems perusahaan sangat mudah melakukan pemantauan dan pengawasan, hal ini dikarenakan perusahaan memiliki sumber daya manusia yang relatif besar, sehingga pengawasan harus lebih mudah dilakukan terutama dalalam pembagian sistem koordinator. Pimpinan dapat memantau kinerja karyawan dengan memantau laporan koordinator divisi masing-masing. Intractive Control Systems dimana karyawan dan atasan dengan menerapkan program pelatihan dan pengembangan. Program ini cukup baik dan berjalan sesuai fungsinya. Komunikasi atasan dengan karyawan secara formal melakukan training, dan secara informal dengan melakukan diskusi.
\end{abstract}

Kata Kunci: : Sistem Pengendalian Manajemen, Levers of Control, Kinerja Karyawan

\begin{abstract}
The management control system and the direction of managers for each company are different. Due to the variables that distinguish each company. Therefore, in this study, we will analyze the application of the theory of Four Levers of Control at PT. Indorama Synthetics Tbk in Purwakarta district, this concept can improve employee performance. The object of this research is textile and other necessities. This study uses a qualitative approach, the method of collecting data sources for this research is carried out by literature studies, interviews and data analysis. Every company needs various control levers that are compatible with company conditions; In Belief Systems Analysis where the company has motivated employees to apply and value and already has a vision, mission and values following company rules. The implementation of this belief system has been communicated through various media such as frames posted on the office walls, on the company website, displayed at internal meetings and during the recruitment process for new employees who are asked about the company's vision and mission. This Boundary Systems company shows that it has realized these limits through the existence of predetermined behavioral limits, where the company PT. Indorama Synthetics Tbk has contained clear and comprehensive rules with sanctions for violations of these behavioral guidelines. The company's Diagnostic Control Systems is very easy to monitor and supervise, this is because the company has relatively large human resources, so supervision must be easier to do, especially in the distribution of the coordinator system. Leaders can monitor employee performance by monitoring the reports of their respective division coordinators. Intractive Control Systems where employees and superiors implement training and development programs. This program is quite good and runs

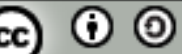

This work is licensed under a Creative Commons Attribution-ShareAlike 4.0 International License. 
according to its function. Communication between superiors and employees is formally through training, and informally by conducting discussions.

Keywords: Management Control System, Levers of Control, Employee Performance

\section{Pendahuluan}

Dalam suatu perusahaan akan mengalami perkembangan dalam dunia bisnis yang dimana menjadi salah satu faktor penting penyebab pertumbuhan perekonomian dunia yang semakin pesat. Untuk memastikan keberlanjutan suatu perusahaan dimasa yang akan datang maka diperlukan adanya strategi yang tepat dan optimal serta dapat memposisikan perusahaan dalam persaingan bisnis dengan baik dan terpercaya. Namun strategi yang baik jika tidak diiringi dengan action belum tentu mampu menghasilkan keberhasilan bagi perusahaan.

Berbagai masalah akan muncul dalam proses pencapaian tujuan tersebut. Masalah yang sering muncul ketika menggunakan sistem pengendalian manajemen adalah kurangnya kepemimpinan oleh manajer atau kepala departemen, kurangnya motivasi dan keterbatasan pribadi. Pada dasarnya karyawan mungkin tidak dapat bekerja dengan cara terbaik, sehingga mempengaruhi tujuan organisasi. Masalah motivasi juga akan mempengaruhi penerapan sistem pengendalian manajemen membuat karyawan tidak loyalitas kepada perusahaan, sehingga karyawan dapat mengambil tindakan yang sesuai kepribadian dan kemauan untuk berkorban tujuan perusahaan. Dan masalah selanjutnya yaitu keterbatasan pribadi seperti kurangnya pengetahuan, pelatihan dan pengalaman profesional saat melakukan tugas. Untuk melaksanakan strategi bisnis suatu perusahaan harus memperhatikan kinerja dari karyawannya dan dimana karyawan tersebut harus memahami dengan baik dan tepat strategi yang akan diimplementasikan untuk mencapai tujuan dari perusahaan. Agar setiap perusahaan atau organisasi memiliki tujuan yang membantu menjaga dinamika perubahan organisasi dan memastikan bahwa tujuan tersebut tercapai dalam perusahaan atau organisasi, diperlukan sistem pengendalian (Mardiasmo, 2009).

Serta perkembangan potensi peran organisasi yang semakin kompleks maka dari itu diperlukan arahan dan kontrol dari pihak management kepada karyawan agar dalam merancang dan mengimplementasikan strategi bisnis dengan baik dan tepat.

Dimana perusahaan juga harus melakukan kendali serta memahami variabel-variabel kunci yang sangat dibutuhkan untuk mempertahankan dan mendukung keberhasilan strategi. Terdapat beberapa 5di perusahaan salah satunya yaitu teori Levers of Control. Dimana sistem Levers of Control terdapat empat control system yaitu (1) Belief System, (2) Boundary System, (3) Diagnostic Control System, dan (4) Interactive Control System (Simons, 1995)
Konsep sistem pengendalian yang diungkapkan oleh (Simons, 2000) yang bertujuan agar para manajemen atau atasan perusahaan dapat mendiagnosa strategi dalam organisasi dan dapat memberikan SPM untuk mempengaruhi strategi dimana SPM ini dapat mencari opportunities, inovasi baru dan menetapkan kapan dan bagaimana mengaplikasikan sistem pengendalian ini lingkungan dalam rangka pencapaian tujuan dan strategi organisasi tersebut (Strauss \& Zacher, 2013).

Berdasarkan uraian di atas, penulis menggabungkan penelitian dengan judul "Analisis Penerapan Model Four Levers of Control (Studi Kasus PT. Indorama Synthetics Tbk Polyester Division di Purwakarta)". Dimana objek penelitian ini yaitu perusahaan PT. Indorama Synthetics Tbk yang merupakan perusahaan multinasional yang memproduksi tekstil dan barang kebutuhan lainnya yang berlokasi di Jatiluhur kabupaten Purwakarta dan berdiri pada tahun 1974.

PT. Indorama Synthetics Tbk merupakan salah satu produsen dan eksportir polyester terbesar di Indonesia dengan total produksi 60 polyester sebesar 280.000 ton pertahun, dan PT. Indorama Synthetics Tbk memiliki empat divisi yaitu polyester division, spinning division, weaving division, dan fabric division. PT. Indorama Synthetics Tbk yang berlokasi di Purwakarta, Subang dan Bandung, Jawa Barat. Penelitian ini hanya dilakukan pada divisi Polyester departemen Poly CP-2 yang berlokasi di Jatiluhur kabupaten Purwakarta, Jawa Barat.

Kemudian perusahan ini dalam Sistem Pengendalian Manajemennya harus dilakukan peningkatan agar kinerja karyawannya meningkat sehingga mampu untuk menghadapi persaingan bisnis multinasional.

Penelitian ini menerapan Four Levers of Control (Simons 2000). Jika keempat model sistem tersebut adalah (1) Belief System yaitu sistem formal yang digunakan oleh manajemen senior untuk mendefinisikan, mengkomunikasikan, memperkuat nilai-nilai inti, tujuan dan aktivitas perusahaan, (2) Boundary System yaitu sistem formal yang digunakan oleh manajemen senior untuk menetapkan batasan dan aturan yang harus diikuti, (3) Diagnotic Control System yaitu sistem umpan balik formal yang digunakan untuk memantau hasil perusahaan dan penyimpangan dari pengukuran kinerja. dan (4) Interactive Control System yaitu sistem formal bagi manajemen senior untuk secara pribadi dan teratur melibatkan bawahan dalam pengambilan keputusan. Penelitian dilakukan pada perilaku karyawan yang berhubungan dengan pengendalian manajemen organisasi contohnya seperti apakah perusahaan 
sudah menerapkan pemberian visi misi yang benar terhadap karyawan untuk meningkatkan kinerjanya, apakah karyawan sudah mentaati peraturan yang ada, sebagai hubungan dua arah antara manajer dan bawahan pada berbagai tingkat organisasi, menjelaskan dan memotivasi karyawan apa yang tidak dapat mereka lakukan, dan menyelaraskan perilaku mereka dengan tujuan organisasi. sehingga karyawan dapat memutuskan tindakan apa yang akan diambil yang dapat mempegaruhi karyawan lain dalam perilaku mereka.

Beberapa penelitian tentang Four Levers of Control telah dilakukan. penelitian yang menggunakan model Four Levers of Control oleh Adhitama dan Aulia (2017) Di Pusat Pendidikan dan Pelatihan Bea Dan Cukai hasil penelitian menunjukkan bahwa perusahaan menerapkan seluruh model Four Levers of Control. Sementara itu pada penelitian yang dilakukan oleh Sri Astuty dan Novia (2015) yang memfokuskan pada penerapan Belief \& Boundary System di PT.Bank Sulselbar yang menunjukkan bahwa PT.Bank Sulselbar telah menerapkan model Four Levers of Control yang khususnya untuk Belief System dan Boundary System. Penelitian yang dilakukan oleh Anandita (2014) di Bank of China Cabang Jakarta yang menunjukkan bahwa telah mengimplementasikan secara natural 3 dari 4 aspek kontrol dalam model Four Levers of Control.

Menurut beberapa penelitian sebelumnya, dapat dilihat bahwa penerapan model Four Levers of Control adalah salah satu cara menentukan bagaimana Sistem Pengendalian Manajemen (SPM) diterapkan oleh perusahaan atau organisasi (Felita 2017). Begitu juga pada PT.Indorama Synthetics Tbk di Purwakarta dalam Sistem Pengendalian Manajemennya harus dilakukan peningkatan agar kinerja karyawannya meningkat sehingga mampu untuk menghadapi persaingan bisnis multinasional. Hal ini menunjukkan bahwa Sistem Pengendalian Manejemen (SPM) harus diterapkan oleh PT.Indorama Synthetics Tbk di Purwakarta dalam persaingan bisnis multinasional saat ini. Berdasarkan latar belakang yang diatas, Penelitian ini bertujuan untuk mengidentifikasi dan menganalisis penerapan berdasarkan kerangka konsep Four Levers of Control pada PT. Indorama Synthetics Tbk Polyester Division Departemen Poly CP-2 dan apakah keseluruhan dari Four Levers of Control tersebut sudah diterapkan pada PT. Indorama Synthetics Tbk Polyester Division Departemen Poly CP-2. Dengan adanya penelitian ini diharapkan dapat memberikan panduan tentang proses manajemen perusahaan saat ini dan tampilan sistem bersadasarkan model Four Levers of Control.

\section{Sistem Pengendalian Manajemen}

Menurut (Sumarsan 2013) Sistem

Pengendalian Manajemen (SPM) adalah serangkaian tindakan dan kegiatan yang terjadi dan terus berlangsung dalam semua aktivitas organisasi.
Pengendalian manajemen bukan hanya sekedar sistem dalam organisasi, tetapi harus dilihat sebagai bagian penting dari setiap sistem yang digunkan oleh manajemen untuk mengatur dan mengelola kegiatannya.

Menurut (Mulyadi 2011) Sistem Pengendalian manajemen adalah suatu sistem untuk merencanakan tujuan masa depan yang ingin dicapai oleh suatu organisasi, merencanakan kegiatan untuk mencapai tujuan tersebut, serta melaksanakan rencana dan pemantauan yang telah dicapai.

Merchant dan (Van der Stede 2014) dalam (Adhitama, 2017) memandang terdapat 3 kategori primer yang sebagai penyebab dalam kasus pengendalian manajemen, yaitu:

a. Kurangnya pengarahan.

b. Masalah motivasi.

c. Keterbatasan Individu.

Menurut (Anthony \& Govindarajan 2000), faktor informal dalam sistem pengendalian manajemen meliputi:

1. Faktor eksternal.

Faktor eksternal adalah norma perilaku yang diharapkan oleh masyarakat dan organisasi perusahaan juga bagian darinya. Standar ini menggabungkan etika profesional melalui kesetiaan, organisasi perusahaan, ketekunan, antusiasme dan efisiensi untuk menyelesaikan tugasnya (Tidak hanya menyelesaikan tugas tepat waktu).

2. Faktor internal.

Faktor-faktor internal dalam sistem pengendalian manajemen antara lain:
a. Budaya.
b. Gaya kepemimpinan.
c. Organisasi informal.
d. Pemahaman dan komunikasi.

\section{Konsep Four Levers of Control}

(Simons, 1995) dalam (Adhitama, 2017) Levers of Control artinya model yang berfokus pada penerapan strategi dalam sistem pengendalian manajemen. Model terdiri dari empat kontrol yang terdiri dari Belief Systems misalnya (nilai inti yang menjadi prinsip pedoman organisasi), Boundary Systems misalnya (kode etik perilaku), Diagnostic Control Systems misalnya (evaluasi kinerja), dan Interactive Control Systems misalnya (partisipasi kepemimpinan). Dari empat model tersebut untuk mengimplementasikannya adalah digunakan secara bersama-sama. Keempat model Levers of Control yaitu : 


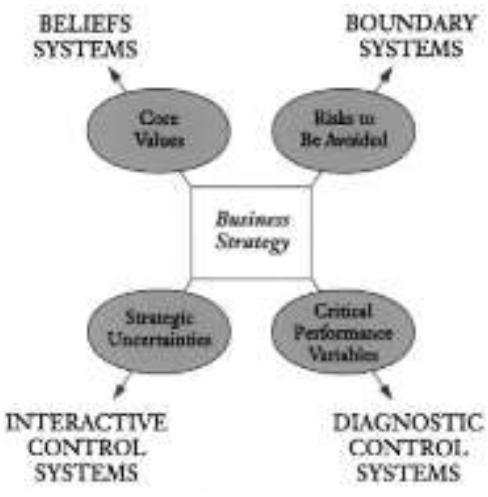

sumber : Simons Robert. 1995.

\section{Gambar 1. Four Levers of Control}

\section{Belief Systems}

Menurut (Simons, 1995) "Belief systems adalah serangkaian defisini organisasi yang jelas, dikomunikasikan secara formal oleh manajer senior, dan secara sistematis diterapkan untuk memberikan organisasi dengan nilai-nilai dasar, tujuan dan arahan." Belief systems dirancang untuk membantu manajer untuk berkomunikasi dan perkuat nilai-nilai yang sulit dipahami oleh karyawan. serta mengkomunikasikan nilai inti dan tujuan organisasi seperti pernyataan visi dan misi yang dikomunikasikan secara aktif, ini berfungsi sebagai pedoman. Dan juga bertujuan untuk memberikan inspirasi dan inovasi kepada karyawan dalam mencari peluang-peluang baru.

\section{Boundary Systems}

Menurut (Simons, 1995) Boundary systems merupakan sistem formal yang digunakan oleh atasan untuk mengatur batasan dan aturan yang harus dipatuhi. Ada dua jenis Boundary systems yaitu business conduct boundaries (kode etik yang menetapkan batasan karyawan) dan strategic boundaries (menjelaskan perilaku yang diizinkan saat mencari peluang oleh karyawan). Yang bertujuan agar karyawan bebas berinovasi dan berprestasi dalam bidang yang sudah ditentukan. Contoh boundary systems adalah sistem yang memuat aturan,batasan, dan larangan dalam kode etik organisasi.

\section{Diagnostic Control Systems}

Menurut (Simons, 1995) Diagnostic control systems bertujuan untuk menghargai motivasi karyawan untuk bekerja dan penyelarasan perilaku karyawan dengan tujuan organisasi melalui pemberian reward. Diagnostic control systems digunakan untuk mengukur kinerja perusahaan, melaporkan faktor kunci sukses (memungkinkan eksekutif untuk fokus pada arah bisnis) dan alat pengawasan yang digunakan untuk melaksanakan strategi yang direncanakan.

\section{Interactive Control Systems}

Menurut (Simons, 1995) Interactive control systems adalah sistem informasi formal yang digunakan manajer untuk secara teratur dan secara pribadi berpartisipasi dalam kegiatan pengambilan keputusan bawahan. Interactive control systems berfokus dengan kebutuhan inovasi dan kreativitas. Tujuannya untuk menyesuaikan organisasi atau perusahaan dengan ketidakpastian strategis sehingga tujuan organisasi atau perusahaan dapat tercapai dengan lancar. Interactive control systems memotivasi karyawan dalam organisasi untuk secara kreatif melakukan pencarian dan memperluas ruang bagi pencarian peluang.

\section{Hubungan Four Levers of Control dengan Strategi Perusahaan}

Hubungan antara keempat model Levers of Control dan strategi perusahaan adalah bahwa sistem pengendalian manajemen dapat diterapkan secara efektif melalui Four Levers of Control yaitu Belief Systems, Boundary Systems, Diagnostic Control Systems dan Interactive Control System dapat digunakan untuk mengendalikan implementasi strategi yang direncanakan oleh perusahaan.

Pada Gambar 1. menjelaskan bahwa sistem pengendalian manajemen dengan metode Four Levers of Control mempunyai empat tools yang saling bersinergi satu sama lain.

Tabel 1. Hubungan Four Levers of Control dengan Stategi Perusahaan

\begin{tabular}{|c|c|c|c|}
\hline $\begin{array}{l}\text { Sistem } \\
\text { Pengendalian }\end{array}$ & Tujuan & $\begin{array}{l}\text { Komunik } \\
\text { asi }\end{array}$ & $\begin{array}{l}\text { Pengendali } \\
\text { an strategi } \\
\text { sebagai }\end{array}$ \\
\hline Belief system & $\begin{array}{l}\text { Mengijinkan } \\
\text { dan memperluas } \\
\text { aktifitas } \\
\text { pencarian }\end{array}$ & Visi & Perspektif \\
\hline $\begin{array}{l}\text { Boundary } \\
\text { system }\end{array}$ & $\begin{array}{l}\text { Memberikan } \\
\text { batasa } \\
\text { kebebasan }\end{array}$ & $\begin{array}{l}\text { Domain } \\
\text { strategi }\end{array}$ & $\begin{array}{l}\text { Posisi } \\
\text { kompetitif }\end{array}$ \\
\hline $\begin{array}{l}\text { Diagnostic } \\
\text { control } \\
\text { system }\end{array}$ & $\begin{array}{l}\text { Koordinasi dan } \\
\text { memantau } \\
\text { implementasi } \\
\text { strategi yang } \\
\text { direncanakan }\end{array}$ & $\begin{array}{l}\text { Rencana } \\
\text { dan } \\
\text { tujuan- } \\
\text { tujuan }\end{array}$ & Rencana \\
\hline $\begin{array}{l}\text { Interactive } \\
\text { control } \\
\text { system }\end{array}$ & $\begin{array}{l}\text { Menstimulasi } \\
\text { dan } \\
\text { mengarahkan } \\
\text { strategi-strategi } \\
\text { yang muncul }\end{array}$ & $\begin{array}{l}\text { Ketidakp } \\
\text { astian } \\
\text { strategi }\end{array}$ & $\begin{array}{l}\text { Pola } \\
\text { tindakan }\end{array}$ \\
\hline
\end{tabular}

sumber : Simons Robert. 1995.

\section{Metode Penelitian}

Penelitian ini menggunakan metode kualitatif, berdasarkan (Creswell, 2007) metode kualitatif metode tersebut adalah metode untuk menggali dan memahami makna yang oleh sejumlah orang atau sekelompok orang yang berasal dari 
masalah sosial atau kemanusiaan. Metode kualitatif juga dapat diartikan sebagai penelitian deskriptif dengan menggunakan pendekatan induktif.

Penelitian ini dilakukan di PT.Indorama Synthetics Tbk Polyester Division Departemen Poly CP-2 yang berlokasi di Kp. Ubrug Desa Kembang Kuning - Kec. Jatiluhur, Purwakarta. Tahapan pengumpulan data malalui wawancara dengan karyawan yang berkompeten,analisis dokumen yang terkait dengan topik yang dibahas, serta riset kepustakaan yang dilakukan meliputi jurnal, referensi artikel dan media internet dengan tujuan untuk memperoleh bahan-bahan yang terkait dengan penelitian.

Dalam penelitian ini yang bertujuan untuk memberikan gambaran mengenai bagaimana penerapan Four Levers of Control pada PT.Indorama Synthetics Tbk Polyester Division Departemen Poly CP-2 tersebut dan ada yang perlu dianalisis dan dipahami beberapa variable dalam proses pengimplementasian strategi agar berjalan dengan baik dan sukses yaitu: 1) core values, 2) risk to be avoided, 3) critical performance variable, dan 4) strategic uncertainties. Manfaat dari penelitian ini yang bertujuan untuk dapat memberikan rekomendasi bagi perusahaan yaitu dengan cara menilai penerapan model Four Levers of Control terhadap kinerja karyawan pada PT.Indorama Synthetics Tbk Polyester Division Departemen Poly CP-2.

\section{Hasil dan Pembahasan}

PT.Indorama Synthetics Tbk merupakan salah satu produsen dan eksportir polyester terbesar di Indonesia dengan total produksi 60 polyester sebesar 280.000 ton pertahun,yang berlokasi di Jatiluhur kabupaten Purwakarta. Dan PT.Indorama Synthetics Tbk memiliki empat divisi yaitu polyester division, spinning division, weaving division, dan fabric division.

Penerapan model Levers of Control menggunakan 4 model yaitu Belief Systems, Boundary Systems, Diagnostic Control Systems dan Interactive Control Systems terhadap kinerja karyawan pada PT.Indorama Synthetics Tbk Polyester Division Departemen Poly CP-2. Berikut analisis penerapan model Four Levers of Control pada PT.Indorama Synthetics Tbk Polyester Division Departemen Poly CP-2 :

\section{Analisis Belief Systems}

pada sistem ini dimana perusahaan telah memotivasi karyawan untuk menerapkan dan nilai dan telah memiliki suatu visi, misi dan tata nilai yang sesuai dengan aturan perusahaan. Pelaksanaan system belief systems ini telah dikomunikasikan melalui berbagai media seperti bingkai yang ditempel di dinding kantor, di website perusahaan, ditampilkan pada pertemuan-pertemuan internal dan pada saat proses rekrutmen karyawan baru ditanyakan mengenai visi misi perusahaan. Hal ini sejalan dengan
Simons (2000) dalam Tero (2009) bahwa belief systems sebagai cerminan perusahaan pada visi dan misi serta tata nilainya digunakan manajer dan diperkuat secara sistematis dalam bentuk formal untuk mengkomunikasikan melalui berbagai media ke seluruh inti badan usaha.

Dimana atasan selalu mengawasi karyawan agar selalu memahami kepedulian dan pemahaman akan belief systems tersebut. Terkait pernyataan tata nilai dan pernyataan misi yang dibuat lebih diarahkan kepada tujuan pencapaian target maka dari pihak perusahaan PT.Indorama Synthetics Tbk Polyester Division Departemen Poly CP-2 melakukan penyampaian secara berulang yang disampaikan ketika pengadaan training untuk karyawan setiap 3 bulan sekali yang dilaksanakan oleh departemen training dalam penyampaian tata nilai dan visi misi kepada semua karyawan, anak magang untuk mengetahui arah organisasi atau badan usaha dengan catatan karyawaan juga mempunyai rasa memiliki dan menjadi bagian dari badan usaha.

\section{Boundary Systems}

Pada sistem ini perusahaan menunjukkan bahwa telah merealisasikan batasan tersebut melalui adanya batasan perilaku yang telah ditetapkan, dimana perusahaan PT.Indorama Synthetics Tbk ini telah memuat aturan-aturan yang jelas dan komprehensif dengan adanya sanksi atas pelanggaran pedoman perilaku tersebut. Penerapannya tidak hanya sebatas pengungkapan informasi tentang peraturan semata dan perusahaan juga memerlukan komitmen nyata, dengan adanya perjanjian ditas kertas secara integritas pada seluruh karyawannya termasuk pihak management. Penerapan kode etik pada perusahaan diterapkan yang berlaku untuk semua karyawan, anggota dewan komisaris, direksi, komite audit dan komite lainnya di PT. Indorama Synthetics Tbk yang harus melaksanakan semua tugas yang diberikan dengan itikad baik, penuh tanggung jawab dan kebijaksanaan.. Sementara itu evaluasi atas strategic boundaries PT.Indorama Synthetics Tbk menunjukkan bahwa perusahaan telah dinyatakan dan dikomunikasikan secara jelas dalam RJP (Rencana Jangka Panjang) perusahaan serta perencanaan strategi yang diperlukan untuk mencapai tujuan perusahaan. Dimana perusahaan melakukan pengembangan bisnis dan pengoperasian usaha.

Pada pengembangan dan pengoperasian usaha ini PT.Indorama Synthetics Tbk sejalan dengan apa yang menjadi Core Competencies perusahaan yaitu sebagai pengembang dan pengoperasi usaha tekstil dan kebutuhan lainnya. Selain itu, perusahaan juga telah menyatakan secara tegas ketentuan dalam investasi saham yang diperbolehkan oleh perusahaan. Agar terhindar dari resiko yang tidak diinginkan dan melakukan pengelolaan atas resiko-resiko tersebut sebagai bagian dari tanggung jawab perusahaan.

\section{Diagnostic Control Systems}


Pada sistem ini perusahaan sangat mudah melakukan pemantauan dan pengawasan, hal ini dikarenakan perusahaan memiliki sumber daya manusia yang relatif besar, sehingga pengawasan harus lebih mudah dilakukan terutama dalalam pembagian sistem koordinator. Pimpinan dapat memantau kinerja karyawan dengan memantau laporan koordinator divisi masing-masing. Selain mengawasi seluruh koordinator divisi perusahaan. Pimpinan perusahaan juga melakukan evaluasi untuk dijadikan sebagai alat untuk meminimalisir kemungkinan terjadinya kesalahan diperusahaan. Hal ini sejalan dengan peneliti Simons (1995) (Adhitama, 2017) bahwa sistem ini mendorong karyawan bekerja lebih efisien dan menyelaraskan perilaku mereka dengan tujuan organisasi. Sistem ini bertujuan untuk meningkatkan antusiasme karyawan melalui sistem umpan balik yang diterapkan secara formal, yang secara aktif memantau aktivitas organisasi. Meskipun tidak dilakukan secara berkala atau konstan, tetapi pemantauan sangat penting dilakukan untuk mengetahui perkembangan program yang dipegang oleh seorang pemimpin organisasi atau perusahaan. Apakah mengalami peningkatan atau mengalami penurunan dan sejauh mana kinerja para karyawannya pada PT.Indorama Synthetics Tbk Polyester Division Departemen Poly CP-2.

Dimana management ingin menerapkan strategi yang dapat mengoptimalkan hasil, pengukuran output,standar evaluasi, dan pemberian reward. Management perusahaan ini melakukan pemberian reward atau penghargaan kepada karyawannya untuk memotivasi mereka mencapai kesuksesan yang lebih besar dan performa kinerja yang lebih baik dari waktu ke waktu. Tidak hanya reward untuk meningkatkan motivasi dan kepuasan kerja. Peningkatan upah, uang lembur, asuransi kesehatan, kesejahteraan sosial (tunjangan), seragam, sepatu, fasilitas yang memadai dan rekreasi setiap tahunnya merupakan cara yang dilakukan perusahaan untuk meningkatkan motivasi dan kepuasan kerja karyawan. Perusahaan memberikan bonus kinerja kepada karyawan tetap dengan mengacu kepada keberhasilan produktifitas dan kelancaran kinerja perusahaan berdasarkan target dan tujuan yang ditentukan oleh perusahaan setiap tahunnya. seperti pemberian jasa kinerja dan penghargaan setiap satu tahun sekali bedasarkan penilaian kinerja karyawan.

\section{Intractive Control Systems}

Pada sistem ini pemimpin sudah cukup baik meskipun ada beberapa karyawan yang tidak suka dengan keputusan tersebut salah satunya masih ada karyawan yang melanggar aturan perusahaan. PT.Indorama Synthetics Tbk Polyester Division Departemen Poly CP-2 menerapkan pada karyawan dan atasan dengan program pelatihan dan pengembangan. Program ini cukup baik dan berjalan sesuai fungsinya. Komunikasi atasan dengan karyawan secara formal melakukan training, dan secara informal dengan melakukan diskusi. Kebebasan berkarya yang perusahaan dengan media atau alat tentukan sangat membantu karyawan untuk mempermudah berekspresi tanpa merasa tertekan, yang penting adalah bagaimana komunikasi itu dilakukan karena dilandasi rasa kekeluargaan agar tidak adanya kerenggangan antara pimpinan dan bawahannya. Dimana PT.Indorama Synthetics Tbk memperhatikan kesejahteraan karyawannya dengan memberikan sarana prasarana yang memadai untuk memenuhi kebutuhan dan meningkatkan motivasi kerja serta kesejahteraan karyawannya.

\section{Kesimpulan}

Berdasarkan hasil analisis dan pembahasan diatas, penulis dapat disimpulkan bahwa PT.Indorama Synthetics Tbk Polyester Division Departemen Poly CP-2 telah menerapkan sistem pengendalian manajemen berdasarkan konsep model Four Levers of Control sebagaimana yang dikemukakan oleh Simons (2000) yaitu meliputi Belief Systems, Boundary Systems, Diagnostic Control Systems, dan Interactive Control Systems bahwa PT. Indorama Synthetics Tbk. Sudah menerapkan konsep ini secara keseluruhan dengan baik.

Adanya keterbatasan dalam pengambilan data management perusahaan dan tidak dilakukannya kuisioner terhadap karyawan. Saran untuk peneliti selanjutnya ialah melakukan analisis perbandingan penerapan model sistem four levers of control dengan model/kerangka pengendalian manajemen lainnya.

\section{Referensi}

Adhitama, S., \& Aulia, D. R. R. (2017). Analisis Penerapan Sistem Pengendalian Manajemen Dengan Model Four Levers of Control Di Pusat Pendidikan Dan Pelatihan Bea Dan Cukai. Info Artha, 1(1), 35-46. https://doi.org/10.31092/jia.v1i1.16

Anandita,D. 2014. Analisis Kemungkinan Penerapan Sistem Pengendalian Manajemen Dengan Model Four Levers of Control di Bank of China Cabang Jakarta. Skripsi Fakultas Ekonomi Universitas Gajah Mada. http://etd.repository.ugm.ac.id/

Anthony, Robert N., dan Govindarajan, Vijay, Sistem Pengendalian Manajemen, Jakarta:Salemba Empat, 2000.

Creswell, John W., Research Design: Qualitative and Quantitative Approaches. Amerika: SAGE Publications, 1994.

Fellita, J. P. (2017). Penerapan Levers of Control Dalam Meningkatkan Kinerja Karyawan Pada Pt Kalisari Citra Jaya. 6(2), 149-168.

Gunawan, I. (2013). KUALITATIF Imam Gunawan. Pendidikan, 143. http://fip.um.ac.id/wp- 
content/uploads/2015/12/3_Metpen-

Kualitatif.pdf

Mardiasmo, Akuntansi Sektor Publik. Yogyakarta, ANDI, 2009

Manajemen, P., Pt, D. I., \& Sulselbar, B. (2015). Levers of Control ( Belief \& Boundary System ): Analisis Sistem. 414-422.

Manggu, S.A.R. Analisis Penerapan Four Levers of Control : Studi Kasus PT. Jasa Marga (Persero) Tbk. Jurnal Creative Ilmiah Vol 3, hal-64

Mulyadi. (2011). Sistem Perencanaan dan Pengendalian Manajemen. Jakarta: Salemba Empat.

Simons, R., 2000. Performance measurement \& control systems for implementing strategy: Text and cases. Upper Saddle River: s.n.

Simons, R., 1995. Levers of Control: How Managers Use Innovative Control Systems to Drive Strategic Renewal. Boston(Massachusetts):
Harvard Business School Press.

Sripeni, R., Hasmoro, A., Broto, K., Ekonomi, F., \& Madiun, U. M. (2017). Pengaruh sistem pengendalian manajemen terhadap kinerja pdam tirta taman sari kota madiun. 6(September).

Strauss, E. \& Zecher, C., 2013. Management Control Systems: A Review. Journal of Management Control, February, Volume 23, pp. 233-26

Sumarsan, Thomas. 2013. Sistem Pengendalian Manajemen, Konsep, Aplikasi dan Pengukuran Kinerja. Edisi 2. Indeks.

Tero, Joanna. 2009. Re-Examining The Levers Of Control-Framework : From Interactive Controls Towards. Helsinki School Of Economics (Hse). Pp. 15-21

Widener, S. K. 2007. An empirical analysis of the levers of control framework. Accounting, Organizations and Society. Vol 3. Pp. 757-788. 